\title{
Validation of Universal Scale in Oral Surgery (USOS) for Patient's Psycho-emotional Status Rating
}

\author{
Inesa Astramskaite ${ }^{1}$, Ginnady Pinchasov ${ }^{1}$, Albinas Gervickas ${ }^{1}$, Dalius Sakavicius ${ }^{1}$, Gintaras \\ Juodzbalys ${ }^{1}$
}

${ }^{1}$ Department of Maxillofacial Surgery, Lithuanian University of Health Sciences, Kaunas, Lithuania.

\author{
Corresponding Author: \\ Inesa Astramskaite \\ S. Lozoraicio g. 9-415, Garliava, Kauno r., LT-53225 \\ Lithuania \\ Phone: +37067 694908 \\ E-mail: inesa.astr@gmail.com
}

\begin{abstract}
Objectives: There aren't any objective methods that may help in standard evaluation of oral surgery patient's psycho-emotional status. Without any standardized evaluation, two main problems appear: heterogeneity between studies and ineffective patient's evaluation. Therefore, Universal Scale in Oral Surgery (USOS) for patient's psycho-emotional status rating has previously been proposed by authors. The aim of present study is to assess the clinical effectivity and validate the Universal Scale in Oral Surgery in case of outpatient tooth extraction for adult healthy patients.

Material and Methods: Clinical trial to validate the USOS for patient's psycho-emotional status rating was performed. In total 90 patients, that came for outpatient dental extraction to Lithuanian University of Health Sciences Oral and Maxillofacial Surgery Department ambulatory, were enrolled in clinical trial. Patients filled self-reported questionnaires before the procedure. Operating surgeon rated USOS for patient's psycho-emotional status rating doctor's part questionnaire after the procedure. 4 - 6 weeks later all patients were asked to fill USOS for patient's psycho-emotional status rating questionnaire retrospectively. Results: According to the statistical analysis, the final composition of USOS for patient's psycho-emotional status rating that would fit to reliability coefficient should be composed from 6 patient part questions and 3 general doctor part questions. Conclusions: Universal Scale in Oral Surgery for patient's psycho-emotional status rating is a novel, doctor and patient rated scale which is suitable for clinical and scientific usage.
\end{abstract}

Keywords: dentistry; fear; oral surgery; pain; psychology.

\author{
Accepted for publication: 30 December 2017 \\ To cite this article: \\ Astramskaite I, Pinchasov G, Gervickas A, Sakavicius D, Juodzbalys G. \\ Validation of Universal Scale in Oral Surgery (USOS) for Patient's Psycho-emotional Status Rating \\ J Oral Maxillofac Res 2017;8(4):e2 \\ URL: http://www.ejomr.org/JOMR/archives/2017/4/e2/v8n4e2.pdf \\ doi: $10.5037 /$ jomr.2017.8402
}




\section{INTRODUCTION}

Patient's discomfort ant doctor's negative emotional feelings in various dental procedures are related to patient's psycho-emotional status during the procedure $[\underline{1}, \underline{2}]$. Three main factors, determining patient's psycho-emotional status, were determined in earlier studies: fear, stress and pain sensitivity $[\underline{2}, \underline{3}]$.

Different elements cause patient's fear, stress and pain sensitivity, therefore in order to improve patient's psycho-emotional status, the causative element should be known $[\underline{1}, \underline{2}]$. Multifactority of human's psychoemotional status is described by anatomy - emotional state depends on amygdala (corpus amygdaloideum) and cerebellum (cerebellum), whose interaction is related to development of fear to negative irritants [4]. This process arises from two steps learning system negative experience may cause fear and corresponding reactions [4]. Dejean et al. [5] stated, that dorsomedial prefrontal cortex is the main location, in which memories causing fear are kept. In this area $4 \mathrm{~Hz}$ frequency vibrations are found during the fearful reactions [5]. Neurologic examinations prove that emotional-physical relationships are firm and negative emotions may cause various reactions in organism: tachycardia, swelling, etcetera $[\underline{4}, 5]$. However, fearcaused changes in brain are not specific. Various emotions may cause different vibrations in specific recurrent cortex locations, therefore it is important to rate full psycho-emotional status complex [6]

When the presence of fears and phobias were examined, dental treatment fear was found to be in top 5 of all fears, and dental treatment phobia number one among other phobias [7]. The level of dental fear may vary according to the upcoming procedure. Oosterink et al. [ $\underline{8}$ ] found that out of 67 dental procedures, oral surgery is the most terrifying for patients. When only oral surgery procedures were examined, the most fear producing procedure was found to be third molar extractions [9].

Pain sensitivity - the other important element of patient's psycho-emotional status, which is described as patient's painful reaction to minimal stimulus and capability to maintain the maximum pain [10]. Even though the pain is usually described as reaction to physical stimulus, it is closely related to patient's psychology. Previous pain experience may generate negative memories, which cause more sensitivity in repeated procedure [5, 7$]$. Also, it is known that stronger pain may be felt if it was anticipated before [11]. Only physical methods to control the pain are not always effective - patient's psycho-emotional status correction is needed in better control of pain, which can be achieved with non-interventional methods [11]

Stress is usually described as physical reactions provoked by negative stimulus, which arise with active sympathetic nervous system and behavioural changes [12]. It should be noted, that fear and felt pain may cause stress $[\underline{5}, 12]$. Also, it was found that prolonged stress may cause chronic pain and vice versa - any pain may induce stressful reactions in human's body [13]. Therefore, in oral surgery physiological reactions of stress and fear arise, because of painful interventions.

Nowadays there are various pharmacological and non-pharmacological methods to control patient's fear, stress and pain sensitivity in dental procedures $[\underline{1}, \underline{2}, 14]$. However, in order to examine effectivity of these methods and overall the problem of patient's psycho-emotional status, measures are needed. In earlier studies it was found that various general instruments are used to rate patient's fear and anxiety before teeth extraction procedures [2]. Because of non-standardized rating, studies become such heterogeneous, that the results are incomparable between each other. The use of different questionnaires often showed different results even in the same situations [2]. Because of their properties and actuality of the problem, there is a need to standardize patient's psycho-emotional status evaluation methods, with a use of practically adaptable measures. Universal Scale in Oral Surgery (USOS) for patient's psycho-emotional status evaluation, composed from patient's reported part and doctor's reported part, was designed in earlier study by Astramskaite and Juodzbalys [15]. The aim of present study is to assess the clinical effectivity and validate the USOS in case of outpatient tooth extraction for adult healthy patients.

\section{MATERIAL AND METHODS Study type}

Perspective Cohort clinical trial was performed between May 2016 and November 2016, at the Department of Oral and Maxillofacial Surgery, Lithuanian University of Health Sciences. The study was registered in online clinical trials register system www.clinicaltrials.gov and can be accessed with number NCT03165448.

\section{Study ethics}

Designed protocol was approved by local centre for biomedical ethics - Bioethics Trials Center, Lithuanian 
University of Health Sciences, on April 6, 2016 and permission was granted with a code BEC-OF- 57 .

All participants had to sign informed consent before enrolling into the study.

\section{Study participants}

All the participants were enrolled into the study according to inclusion and exclusion criteria. The inclusion criteria were developed using the PICOS guidelines [16].

\section{Inclusion criteria}

- Adult patients (18 years and more), who need routine tooth extraction.

- No contraindications for outpatient tooth extraction.

- Tooth extraction with local anaesthesia.

- Voluntary participation in the study.

- Patients, which can fill questionnaires and enrol in the study by selves.

\section{Exclusion criteria}

- Under-age patients and adult patients, who need inpatient tooth extraction.

- Contraindications for outpatients tooth extraction.

- Tooth extraction with general anaesthesia or sedation.

- Disagreement of participation in study.

- Patients that have communication disorders due to disease or age.

All the participants were divided into groups according to these criteria: sex, age, experience of oral injection anaesthesia, and experience of oral surgery procedures.

Sample size of clinical trial was calculated according to statistical sample size formula listed below and Hertzog [17] recommendations for pilot clinical trials:

$$
\mathrm{n}=\frac{1}{\Delta^{2}+1 / \mathrm{N}}
$$

$\Delta=0.05, \mathrm{~N}=$ population size

According to sample size formula it was calculated that population representing sample size is 372 people. According to Hertzog [17] recommendations, the pilot clinical trial's sample size should provide more than $10 \%$ of needed sample size and with higher than 30 participants in a study. The selection of study participants is showed in flow chart below (Figure 1).

\section{Study design}

Evaluation of patient's psycho-emotional status was performed using questionnaires in various times to tooth extraction procedure, involving patient's evaluation and doctor's evaluation. The study was performed in three stages (Figure 2).

\section{Scales used for patient's psycho-emotional status evaluation \\ Main scale}

USOS is a questionnaire, composed of two parts: patient-reported part and doctor-reported part, and is a main scale in present study. It was developed and suggested by authors in earlier studies $[\underline{2}, \underline{15}]$. USOS is a numerical scale with $1-3$ numerical choices to every item. Patient's part questionnaire is composed from eight items, representing patient's pain sensitivity, stress and fear (Appendix 1).

Doctor's USOS part is composed from three general items with guidelines, how to rate patient's pain sensitivity, stress and fear. All the items must be rated in three points system as well (Appendix 2).

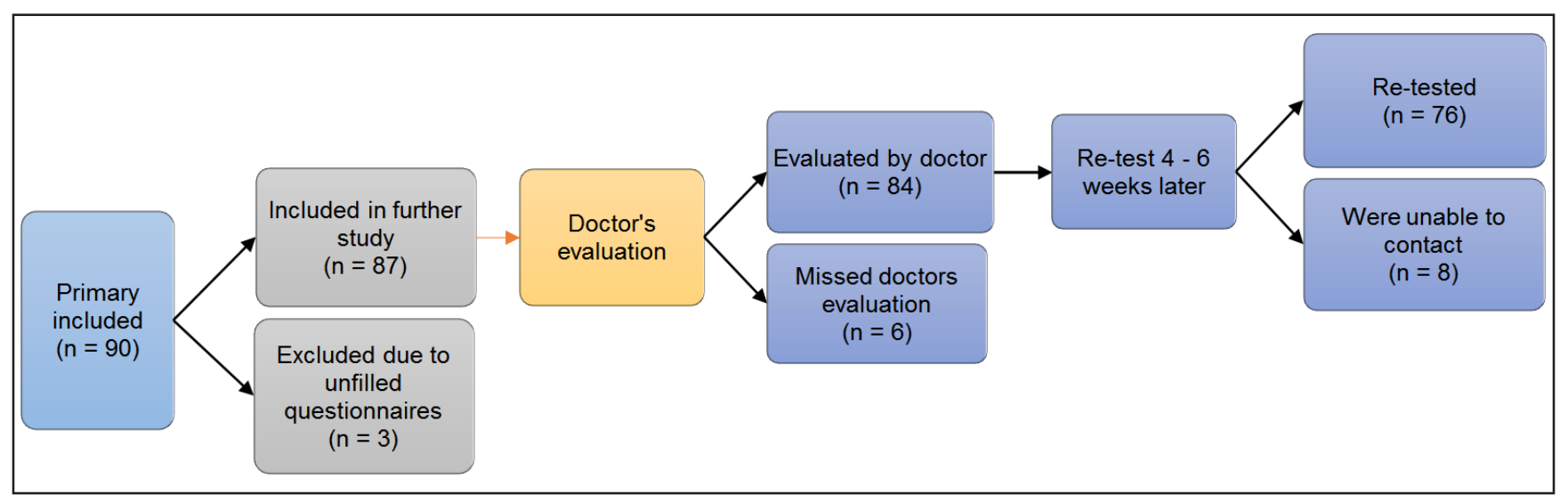

Figure 1. Flow chart for selection of study participants. 


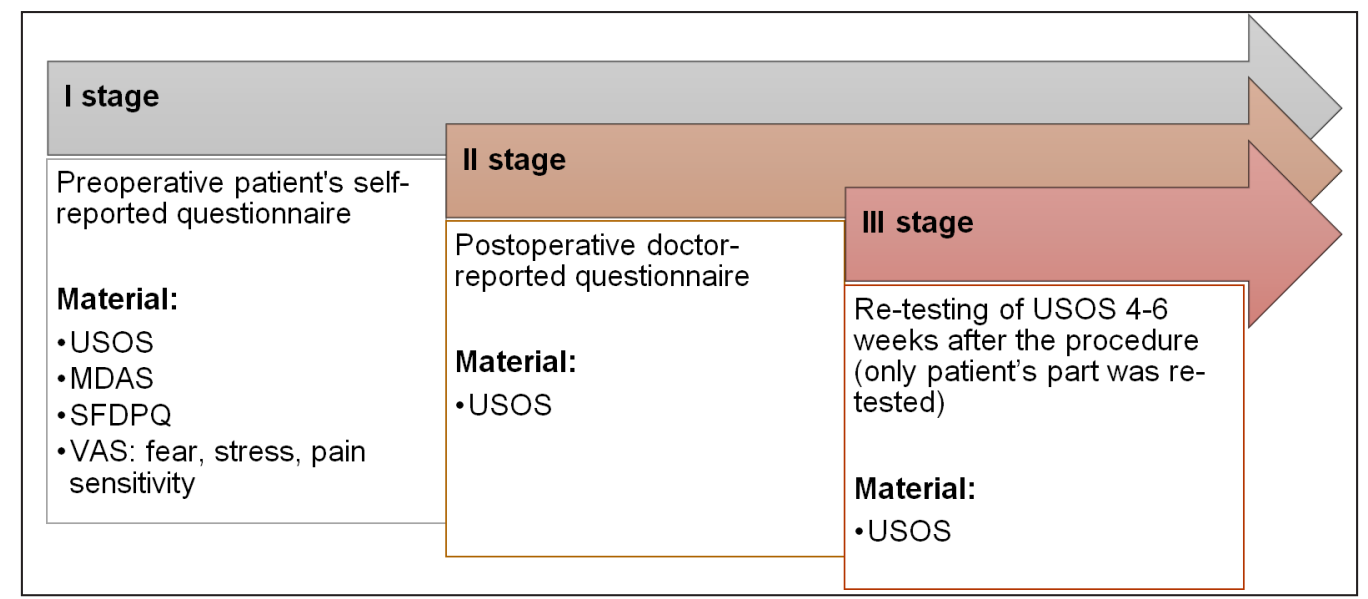

Figure 2. Study design scheme.

USOS = Universal Scale in Oral Surgery for psycho-emotional status rating; VAS = Visual Analogue Scale; SFDPQ = Short version of Fear of Dental Pain Questionnaire; MDAS = Modified Dental Anxiety Scale.

Original scale is designed to be rated by operating surgeon. However, to rate inter-examiner evaluation correlation, every patient was rated by operating oral and maxillofacial surgeon and additional general dental practitioner. All the doctors involved in study were permanent workers in Lithuanian University of Health Sciences. Kappa index was calculated for both pairs [18].

\section{Control scales}

Control scales were selected to rate the correlation between them and USOS. However, no double rating scales, involving doctor as well as patient in rating process, were found [15]. Therefore, only patientreported popular questionnaires were selected as control scales:

Short version of Fear of Dental Pain Questionnaire (SFDPQ) was chosen for present study, to represent patient's fear of pain. This questionnaire was constructed in 2006 by van Wijk et al. [19] as convenient instrument for patient's fear of dental pain rating. This questionnaire is composed from five items with a task to rate each procedure listed in 5-points scales according to the fear of pain in these procedures. Procedures listed in SFDPQ [19]:

- Receiving an anaesthetic injection in the mouth;

- Having a tooth drilled;

- Receiving root canal treatment;

- Having a tooth pulled;

- Having a wisdom tooth extracted.

Modified Corah's Dental Anxiety Scale (MDAS) questionnaire was chosen for this study, since Corah's Dental Anxiety Scale questionnaire and MDAS was found to be one of the most frequently used dental anxiety questionnaires in tooth extraction patient's fear evaluation [2]. MDAS is a five questions scale with 1 - 5 points representing "not anxious - very anxious" rating to each item. Questions of MDAS [20]:

- If you went to your dentist for treatment tomorrow, how would you feel?

- If you were sitting in waiting room (waiting for treatment), how would you feel?

- If you were about to have your teeth drilled, how would you feel?

- If you were about to get your teeth scaled and polished, how would you feel?

- If you were about to get local anaesthetic injection in your gum, above an upper back tooth, how would you feel?

Visual Analogue Scale (VAS) is a common instrument, used in pain assessment in medicine [21]. There are various methods of using VAS, but authors chosen 10-points rating instrument for present clinical trial [15]. Patients were asked to rate following factors in a scale from 1 to 10 :

- Fear to the upcoming procedure.

- Stress to the upcoming procedure.

- Pain, that is expected in upcoming procedure.

\section{Additional questions}

In brief, general additional questions included information about patient's sex, age, injection anaesthesia experience, oral surgery procedures experience. Also, patients with oral surgery experience, had to choose which oral surgery procedures they have experienced: mobile tooth extraction, non-mobile tooth simple extraction, operative tooth extraction, implantation, tumour removal in oral cavity, incisions in oral cavity (due to abscesses, frenuloplasties etc.), other. 


\section{Translation}

All the scales included in present study were found in original English language [15,19-21]. Therefore, double-translation method was performed to obtain accurate translated questionnaires, as suggested by World Health Organization for medical questionnaires translation [22]. This method involves primary English questionnaire translation to local language by investigator, whose English is a second language. Afterwards expert investigator revises the translated questionnaire and re-translates items to English language. The comparison between original and retranslated English scales is then revised. Any mistakes should be corrected during this process [22].

\section{Statistical analysis}

Statistical analysis was performed with SPSS 12.0 for windows. Statistical significance was when $\mathrm{P}<0.05$.

Statistical analysis sample size parameters with narrative statistics was performed and specific statistical evaluations: Student t-test; Wilcoxon; Pearson correlation; Spielberg correlation; Cronbach's alpha; KMO and Barlett's test; ANOVA.

\section{RESULTS}

In total 90 participants, who met the inclusion criteria, were included in the study. Three patients were excluded from further examinations because of unfilled questionnaire. Out of 87 included patients, 60 were females and 27 males. In total there were 31\% of participants younger than 25 years, $28.7 \%-25$ to 40 years old, $25.3 \%$ - 40 to 60 years old and the rest were older than 60 years. No statistically significant differences were found among these groups. In total, eighty four patients' psycho-emotional status was rated by operating doctors. Seventy six participants repeated the USOS questionnaire 4 - 6 weeks later.

The Kappa index for examining doctor's pairs was $\kappa=0.84$ and $\kappa=0.79$. No statistically significant differences were found between general practitioner and oral and maxillofacial surgeon evaluations.

Sex and age did not influence the results of USOS. However, women showed higher scores in SFDPQ $(\mathrm{P}=0.023)$ than men. Also, it was found that 18 - 25 years age participants rated SFDPQ higher $(P=0.007)$ than those $40-60$ years old. $25-40$ years old participants showed higher scores with SFDPQ $(P=0.007)$ and VAS pain question $(P=0.037)$ compared to 40 - 60 years old patients.

When different experiences were examined it was found that patients without injection anaesthesia $(P=0.001)$ and oral surgery procedures $(0.019)$ experience were rated more negatively by doctors. Also, patients without oral surgery procedures experience showed higher scores in VAS fear $(P=0.031)$ and stress $(P=0.029)$ questions. Evaluating different procedures experience influence, it was found that those with common immobile tooth extraction experience were in better psycho-emotional status according to MDAS ( $\mathrm{P}=0.026)$, VAS fear $(\mathrm{P}=0.013)$ and stress $(\mathrm{P}=0.05)$ question and USOSdoctor part $(\mathrm{P}=0.017)$. Other procedures did not influence the outcomes.

Various internal reliability tests were applied for USOS. When internal reliability test was calculated on eight questions Cronbach's alpha was 0.688 for patient's part and 0.757 for doctor's part questionnaire separately. Cronbach's alpha for complete USOS is 0.757 and 0.741 for re-tested USOS. The correlation between USOS and re-tested USOS questionnaires was found to be statistically significant $(\mathrm{P}=0.000$; $r=0.574$; Spearman correlation). Statistically significant correlation was also found between patients and doctor's results $(\mathrm{P}=0.000 ; \mathrm{r}=0.446)$. It was noted that patients were more prone to overrate their psycho-emotional status and chose the higher maximum values than the doctors $\operatorname{did}(\mathrm{Z}=-5.348$; $\mathrm{P}=0.000)$.

When Cronbach alpha, if items are deleted, test was applied, it was found that interval reliability rises up, when items number seven and eight are removed. Cronbach's alpha for six questions of primary USOS reaches 0.783 and 0.753 for re-tested USOS.

The other test of internal reliability (KMO-Barlett test) showed index of 0.692 for eight USOS questions and 0.755 and 0.752 respectively, when question number 8 or 7 were removed. KMO-Barlett test and two components factorial matrix analysis showed that reliability coefficients increase, when questions number 7 and 8 are removed (Figure 3).

Statistically significant correlations $(\mathrm{P}<0.005)$ were observed between USOS and all additional questionnaires used in present study (Table 1).

\section{DISCUSSION}

The aim of present study was to validate the scale, which was proposed earlier by same authors, and to check the effectivity and reliability of universal scale in oral surgery in clinical practice. After literature review it was found that self-reported questionnaires are mostly used as the only method for patient's psycho-emotional status evaluation [15] . 


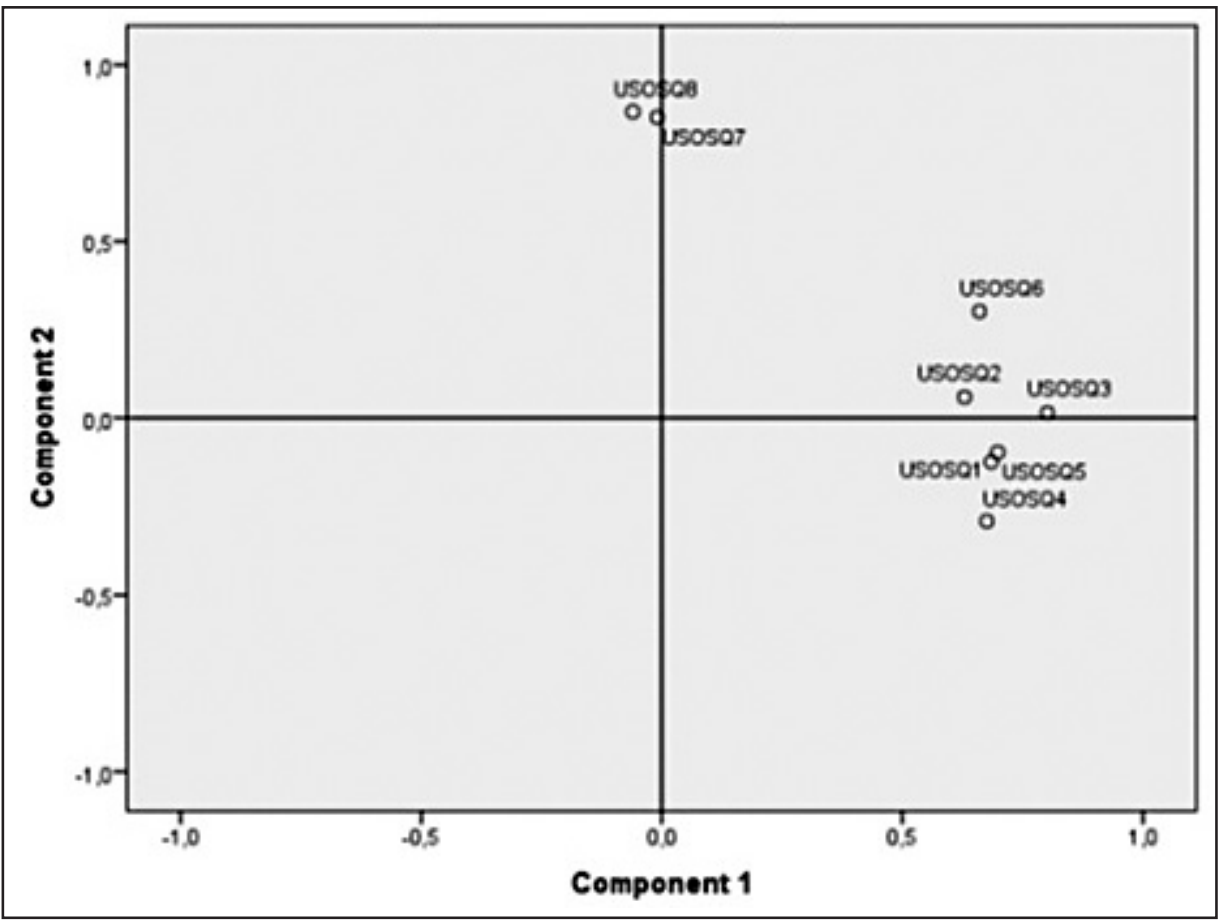

Figure 3. Two components matrix analysis for Universal Scale in Oral Surgery for psycho-emotional status rating questions.

Table 1. Correlations between all questionnaires used

\begin{tabular}{|c|c|c|c|c|c|c|c|c|}
\hline & USOS & USOS re-test & USOS-doctor & VAS-fear & VAS-stress & VAS-fear & SFDPQ & MDAS \\
\hline USOS & - & $\begin{array}{l}r=0.574 \\
P=0.000\end{array}$ & $\begin{array}{l}r=0.446 \\
P=0.000\end{array}$ & $\begin{aligned} \mathrm{r} & =0.55 \\
\mathrm{P} & =0.000\end{aligned}$ & $\begin{array}{l}r=0.603 \\
P=0.000\end{array}$ & $\begin{aligned} \mathrm{r} & =0.54 \\
\mathrm{P} & =0.000\end{aligned}$ & $\begin{array}{l}r=0.441 \\
P=0.000\end{array}$ & $\begin{array}{l}\mathrm{r}=0.538 \\
\mathrm{P}=0.000\end{array}$ \\
\hline USOS re-test & - & - & $\begin{array}{l}\mathrm{r}=0.348 \\
\mathrm{P}=0.002\end{array}$ & $\begin{array}{c}r=0.6 \\
P=0.000\end{array}$ & $\begin{array}{c}\mathrm{r}=0.548 \\
\mathrm{P}=0.000\end{array}$ & $\begin{array}{l}\mathrm{r}=0.425 \\
\mathrm{P}=0.000\end{array}$ & $\begin{array}{l}r=0.376 \\
P=0.000\end{array}$ & $\begin{array}{l}\mathrm{r}=0.594 \\
\mathrm{P}=0.000\end{array}$ \\
\hline USOS-doctor & - & - & - & $\begin{array}{l}\mathrm{r}=0.413 \\
\mathrm{P}=0.000\end{array}$ & $\begin{array}{l}\mathrm{r}=0.444 \\
\mathrm{P}=0.000\end{array}$ & $\begin{array}{l}\mathrm{r}=0.334 \\
\mathrm{P}=0.000\end{array}$ & $\begin{array}{l}\mathrm{r}=0.414 \\
\mathrm{P}=0.000\end{array}$ & $\begin{array}{l}\mathrm{r}=0.465 \\
\mathrm{P}=0.000\end{array}$ \\
\hline VAS-fear & - & - & - & - & $\begin{array}{l}\mathrm{r}=0.857 \\
\mathrm{P}=0.000\end{array}$ & $\begin{array}{l}\mathrm{r}=0.697 \\
\mathrm{P}=0.000\end{array}$ & $\begin{array}{l}r=0.652 \\
P=0.000\end{array}$ & $\begin{array}{l}\mathrm{r}=0.683, \\
\mathrm{P}=0.000\end{array}$ \\
\hline VAS-stress & - & - & - & - & - & $\begin{array}{l}\mathrm{r}=0.715 \\
\mathrm{P}=0.000\end{array}$ & $\begin{array}{l}\mathrm{r}=0.626 \\
\mathrm{P}=0.000\end{array}$ & $\begin{array}{l}r=0.664 \\
P=0.000\end{array}$ \\
\hline VAS-pain & - & - & - & - & - & - & $\begin{array}{l}r=0.631 \\
P=0.000\end{array}$ & $\begin{array}{l}r=0.536 \\
P=0.000\end{array}$ \\
\hline SFDPQ & - & - & - & - & - & - & - & $\begin{array}{l}r=0.723, \\
P=0.000\end{array}$ \\
\hline MDAS & - & - & - & - & - & - & - & - \\
\hline
\end{tabular}

USOS = Universal Scale in Oral Surgery for psycho-emotional status rating; VAS = Visual Analogue Scale; SFDPQ = Short version of Fear of Dental Pain Questionnaire; MDAS = Modified Dental Anxiety Scale.

However, the scales that are used nowadays are constructed to rate only patient's opinion and it rates only single components of psycho-emotional status, without complex evaluation of stress, fear and pain sensitivity. Because of these problems, the clinical trial, for reliability and effectivity of USOS for patient's psycho-emotional status evaluations, was constructed $[\underline{2}, \underline{15}]$.

It was found that young patients had less experience in oral anaesthesia injection and oral surgery procedures than older patients. In earlier studies it was noted that injection anaesthesia can be even more fearful than surgical procedure [23]. Because of this, injection anaesthesia, same as all surgical procedures, have negative effect on patient's psycho-emotional status. However, the results of age influence on patient's psycho-emotional status are controversial, since young patients have low experience. [2,24]. In our clinical trial age did not influence the results, but it was found that inexperienced patients rated VAS fear and stress with higher degrees. Moreover, the doctors rated inexperienced patients more 
negative, compared to experienced ones. Shitole et al. [25] stated that young, inexperienced patients may feel higher anxiety than other patients. On the other hand, Flor [26] noted that the negative painful dental experience affect psychical state and negative memories are generated in mind, with the result of stress and vegetative nervous system symptoms.

Sex influence was found only with SFDPQ questionnaire, where women showed statistically significantly higher results than men. These findings are common, since women are usually prone to higher anxiety [2,23]. This phenomenon could be related to statistically significantly higher amounts of grey matter in specific areas of brain cortex for women than men, which could influence biological nature for different emotional behaviour [24]. Separate oral surgery procedures experience mostly was related to teeth extractions. It is also common result, when ambulatory oral surgery procedures are evaluated $[24,25]$. It is interesting, that operative tooth extraction increased patient's anxiety, when simple immobile tooth extraction improved patient's psychoemotional status. It could be related to different memories generation in brain, i.e. the simple tooth extraction procedure produced positive memories and the operative tooth extraction negative, resulting in different amounts of fear $[\underline{26}, \underline{27}]$. These results prove that negative memories may affect patient's present behaviour [2, 26] .

All the patients included in present trial were rated by paired doctors - general dental practitioner and oral and maxillofacial surgeon. Kappa indexes were high for both pairs with no statistically significant differences between examiners [18]. It is not surprising, since in both - general dentistry and oral surgery - patient's psycho-emotional problems are common [8]. However, there were no studies found evaluating the correlations between general dental practitioner's and oral and maxillofacial surgeon's abilities in patient's psycho-emotional status evaluation.

The validation process of newly formed scale was based on internal reliability, correlations with coexisting scales, test-retest coefficient calculations. Cronbach's alpha was used as internal reliability coefficient, which showed appropriate internal reliability for all the scales used. There are various opinions based on Cronbach's alpha suitability on internal reliability calculations, since this coefficient is affected by number of questions - the more questions, the higher the Cronbach's alpha. Usually, if Cronbach's alpha is lower than 0.5 the scale is considered to be unreliable, but higher Cronbach's alpha than 0.9 shows possible excess and repeatable questions [28]. After statistical analysis, it was found that when items number 7 and 8 are removed from USOS, Cronbach's alpha reaches 0.783 for patient's part and 0.757 for doctor's part. After USOS KayserMeyer (MSA) rating, it was found that MSA is appropriate $(>0.5)$ for all the items, except number 7 and 8 . This statistical method lets to rate each items correlations with general scale results. It means, that every item is calculated as independent element for patient's evaluation and these statistical methods let check the elements suitability with general scale. Even though the suitable MSA is described as $>0.5$, when scales are used in practice, MSA is recommended to be $>0.6$ [29]. In order to increase the internal reliability, which is crucial for psychometrical scales, authors have decided to exclude questions number 7 and 8 from final questionnaire.

USOS correlation with other questionnaires showed statistically significant, however low $(r<0.5)$, correlations. All correlations were calculated according to sum of points in every questionnaire in order to see whether the rise up of the points influence the rise up of the points in other questionnaire. However, it should be noted that all questionnaires used are for patient's evaluation in general dentistry. These were chosen as control scales, according to previously reported systematic review results that showed these scales popularity in oral surgery patient's evaluation [15]. The correlation with other scales that are used in similar evaluation is needed for scale's external reliability testing - to show, if the scale shows similar results to the others. Despite the correlations between different scales, results didn't show the same in all scales and in all situations. It can be explained by multicomplexity of USOS, since stress, fear and pain sensitivity are rated at once. Even though these three elements are close to each other, one dominant factor may be present,

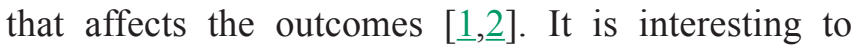
note that patient-doctor USOS correlation is lower, when patient's retested results are compared. This can be influenced because of the change in patient's status after some time after the procedure. In earlier studies it was found, that patient's emotional change may be affected by the procedure and postoperative period [2]. Without negative memories of procedure, patient's state after some time may be improved. However, after difficult procedures and painful postoperative period patient may feel higher fear and pain for upcoming procedures $[2,26]$. Because of this, patient's psycho-emotional status should be repeatedly checked to note possibly changed patient's state [27]. The evaluation of questionnaire was based not only on standard rating of mean, but also with a look in 
maximum values. It is interesting that doctors usually rated patients with lower values than patients did and only in 4 cases the maximum evaluations concurred. McDonald [30] published a study, in which she had criticized the self-reported questionnaires as only instruments for psychological conditions evaluation because of possibility to mimic results. One of advised alternatives - combination of self-reported questionnaires and additional assessor, what was completed in present study [30]. Based on this theory, we may believe that patients reaching for unpainful, non-stressful surgical procedures may intentionally or unintentionally overrate their fear $[26,30]$. With the aim of improving the objectivity of patient's psycho-emotional status evaluation, we recommend that questionnaires analysis should be combined with additional tests, such as biochemical changes in human's body tracking, that help to evaluate physical reactions, caused by psychological conditions $[15, \underline{27}, \underline{30}]$.

According to the observed results from statistical analysis, literature data and from own experience the final USOS composition was modified excluding items number 7 and 8 . Therefore, the final USOS is constructed from six patient reported questions and three general doctors reported questions with 1 to 3 points selection to each item. The final analysis of USOS questionnaires should be based on mean values of patient's part questionnaire and doctors' part questionnaire with following values:

- 0,1 positive psycho-emotional status.

- 1,2 medium psycho-emotional status.

- 2, 3 negative psycho-emotional status.
The main evaluation should be taken on higher mean doctor's or patient's in order to achieve the maximum care for the patient.

The final composition of USOS is shown in Appendix 3.

\section{CONCLUSIONS}

Universal Scale in Oral Surgery for patient's psychoemotional status rating is a suitable instrument for patient's psycho-emotional status evaluation in oral surgery due to practical or scientific needs. The double rating, including doctor and patient, improves the objectivity of self-reported questionnaires. Also, 3-points evaluations eases the interpretation of results. However, some notes should be kept in mind:

1. Further multi-centre studies to validate Universal Scale in Oral Surgery for patient's psychoemotional status rating in wide populations are needed.

2. Further studies to standardize the additional instruments usage together with Universal Scale in Oral Surgery should be done.

\section{ACKNOWLEDGMENTS AND DISCLOSURE STATEMENTS}

The authors declare that there are no financial or other conflicts of interest related to this publication.

\section{REFERENCES}

1. Brahm CO, Lundgren J, Carlsson SG, Nilsson P, Hultqvist J, Hägglin C. Dentists' skills with fearful patients: education and treatment. Eur J Oral Sci. 2013 Jun;121(3 Pt 2):283-91. [Medline: 23659263] [doi: 10.1111/eos.12017]

2. Astramskaite I, Poškevičius L, Juodžbalys G. Factors determining tooth extraction anxiety and fear in adult dental patients: a systematic review. Int J Oral Maxillofac Surg. 2016 Dec;45(12):1630-1643. [Medline: 27436789] [doi: 10.1016/j.ijom.2016.06.019]

3. Carter AE, Carter G, Boschen M, AlShwaimi E, George R. Pathways of fear and anxiety in dentistry: A review. World J Clin Cases. 2014 Nov 16;2(11):642-53. [Medline: 25405187] [PMC free article: 4233415] [doi: 10.12998/wjcc.v2.i11.642]

4. Magal A, Mintz M. Inhibition of the amygdala central nucleus by stimulation of cerebellar output in rats: a putative mechanism for extinction of the conditioned fear response. Eur J Neurosci. 2014 Nov;40(10):3548-55. [Medline: 25185877] [doi: 10.1111/ejn.12714]

5. Dejean C, Courtin J, Karalis N, Chaudun F, Wurtz H, Bienvenu TC, Herry C. Prefrontal neuronal assemblies temporally control fear behaviour. Nature. 2016 Jul 21;535(7612):420-4. [Medline: 27409809] [doi: 10.1038/nature18630]

6. Adolphs R. The biology of fear. Curr Biol. 2013 Jan 21;23(2):R79-93. [Medline: 23347946] [PMC free article: 3595162 ] [doi: 10.1016/j.cub.2012.11.055]

7. Oosterink FM, de Jongh A, Hoogstraten J. Prevalence of dental fear and phobia relative to other fear and phobia subtypes. Eur J Oral Sci. 2009 Apr;117(2):135-43. [Medline: 19320722] [doi: 10.1111/j.1600-0722.2008.00602.x]

8. Oosterink FM, de Jongh A, Aartman IH. What are people afraid of during dental treatment? Anxiety-provoking capacity of 67 stimuli characteristic of the dental setting. Eur J Oral Sci. 2008 Feb;116(1):44-51. [Medline: 18186731] [doi: 10.1111/j.1600-0722.2007.00500.x] 
9. Sirin Y, Humphris G, Sencan S, Firat D. What is the most fearful intervention in ambulatory oral surgery? Analysis of an outpatient clinic. Int J Oral Maxillofac Surg. 2012 Oct;41(10):1284-90. [Medline: 22832662] [doi: 10.1016/j.ijom.2012.06.013]

10. Mostoufi S, Godfrey KM, Ahumada SM, Hossain N, Song T, Wright LJ, Lohr JB, Afari N. Pain sensitivity in posttraumatic stress disorder and other anxiety disorders: a preliminary case control study. Ann Gen Psychiatry. 2014 Nov 18;13(1):31. [Medline: 25422670] [PMC free article: 4236800] [doi: 10.1186/s12991-014-0031-1]

11. McNeil DW, Helfer AJ, Weaver BD, Graves RW, Kyle BN, Davis AM. Memory of pain and anxiety associated with tooth extraction. J Dent Res. 2011 Feb;90(2):220-4. [Medline: 21149859] [doi: 10.1177/0022034510385689]

12. Atlas LY, Wager TD. How expectations shape pain. Neurosci Lett. 2012 Jun 29;520(2):140-8. [Medline: 22465136] [doi: 10.1016/j.neulet.2012.03.039]

13. Ramsey A, Rolnick K, Smith R, Weng C, Li Y, Lokuta A. Activation of Human Sympathetic nervous system: effects on memory performance. JASS. 2012 Spring;1. [URL: http://jass.neuro.wisc.edu/]

14. Cathcart S, Bhullar N, Immink M, Della Vedova C, Hayball J. Pain sensitivity mediates the relationship between stress and headache intensity in chronic tension-type headache. Pain Res Manag. 2012 Nov-Dec;17(6):377-80. [Medline: 23248808] [PMC free article: $\underline{3659009}$ ] [doi: 10.1155/2012/132830]

15. Astramskaitė I, Juodžbalys G. Scales used to rate adult patients' psycho-emotional status in tooth extraction procedures: a systematic review. Int J Oral Maxillofac Surg. 2017 Jul;46(7):886-898. [Medline: 28377143] [doi: 10.1016/j.ijom.2017.03.015]

16. da Costa Santos CM, de Mattos Pimenta CA, Nobre MR. The PICO strategy for the research question construction and evidence search. Rev Lat Am Enfermagem. 2007 May-Jun;15(3):508-11. [Medline: 17653438] [doi: 10.1590/S0104-11692007000300023]

17. Hertzog MA. Considerations in determining sample size for pilot studies. Res Nurs Health. 2008 Apr;31(2):180-91. [Medline: 18183564] [doi: 10.1002/nur.20247]

18. McHugh ML. Interrater reliability: the kappa statistic. Biochem Med (Zagreb). 2012;22(3):276-82. [Medline: 23092060] [PMC free article: $\underline{3900052}]$

19. van Wijk AJ, McNeil DW, Ho CJ, Buchanan H, Hoogstraten J. A short English version of the Fear of Dental Pain questionnaire. Eur J Oral Sci. 2006 Jun;114(3):204-8. [Medline: 16776769] [doi: 10.1111/j.1600-0722.2006.00350.x]

20. Freeman R, Clarke HM, Humphris GM. Conversion tables for the Corah and Modified Dental Anxiety Scales. Community Dent Health. 2007 Mar;24(1):49-54. [Medline: 17405471]

21. Bijur PE, Silver W, Gallagher EJ. Reliability of the visual analog scale for measurement of acute pain. Acad Emerg Med. 2001 Dec;8(12):1153-7. [Medline: 11733293] [doi: 10.1111/j.1553-2712.2001.tb01132.x]

22. Chávez LM, Canino G. Toolkit on Translating and Adapting Instruments. Cambridge, MA: Human Services Research Institute. 2005. [URL: www.tecathsri.org]

23. Lone PA, Singh M, Salgotra V. Minor surgical procedures and pre operative anxiety. J Dent Med Sci. 2015 Jul;14(7): 96-101. [doi: 10.9790/0853-147496101]

24. Da Costa RSM, Ribeiro SDN, Cabral ED. Determinants of painful experience during dental treatment. Rev Dor. 2012 Dec;13(4):365-70. [doi: 10.1590/S1806-00132012000400011]

25. Shitole S, Kumar MCD, Suresh KV, Parkar MI, Patil PB, Ashwinirani SR. Assessment of Dental Anxiety in Patients Undergoing Surgical Extraction of Teeth: Study from Western Maharashtra. Brit Biomed Bulletin. 2015 Jan;3(2):232-8. [URL: http://bbbulletin.org]

26. Flor H. Psychological pain interventions and neurophysiology: implications for a mechanism-based approach. Am Psychol. 2014 Feb-Mar;69(2):188-96. [Medline: 24547804] [doi: 10.1037/a0035254]

27. Umeanuka OT, Saheeb BD, Uguru CC, Chukwuneke FN. Evaluation of cortisol concentrations in saliva as a measure of stress in patients having routine dental extractions. Br J Oral Maxillofac Surg. 2015 Jul;53(6):557-60. [Medline: 25886877] [doi: 10.1016/j.bjoms.2015.03.011]

28. Tavakol M, Dennick R. Making sense of Cronbach's alpha. Int J Med Educ. 2011 Jun 27;2:53-55. [Medline: 28029643] [PMC free article: 4205511] [doi: 10.5116/ijme.4dfb.8dfd]

29. Anastasiadou SD. Reliability and validity testing of a new scale for measuring attitudes toward learning statistics with technology. Act Didact Napocens. 2011;4(1):1-10. [URL: http://adn.teaching.ro/]

30. McDonald JD. Measuring Personality Constructs: The Advantages and Disadvantages of Self-Reports, Informant Reports and Behavioural Assessments. J Enquire. 2008 Jan;1(1):75-94. [URL: https://www.nottingham.ac.uk] 
Appendix 1. Patient's part of Universal Scale in Oral Surgery for psycho-emotional status rating.

\section{PATIENT QUESTIONNAIRE}

Instruction: Please circle one numerical choice next to every following question.

Numerical meanings are listed above:

1 - disagree/low value.

2 - neither agree or disagree/the middle value.

3 - agree/high value.

\section{PART I}

1. Rate the highest pain in your previous oral surgery procedure (rate the pain level as 1 if you never had such a procedure before).
1
2
3

2. Rate the highest pain that you are expecting in upcoming oral surgery procedure.

2

3

\section{PART II}

1. I am feeling helpless during the procedures in oral surgery.

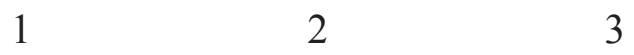

2. My heart beats faster before the surgical procedure.

123

3. My respiratory rate is higher before the surgical procedure.

123

\section{PART III}

1. Rate the intention of cancelling the appointment of oral surgery procedure.

123

2. Rate the trust in doctor, who is going to perform your surgery.

123

3. Rate the understanding of why you have to undergo the upcoming procedure.

2

3 
Appendix 2. Doctor's part of Universal Scale in Oral Surgery for psycho-emotional status rating.

\section{DOCTOR'S QUESTIONNAIRE}

Instruction: Rate the patient's pain sensitivity, stress and fear according to seen response in numerical rating.

\section{Numerical rating meanings are listed above:}

1 - low value.

2 - the middle value.

3 - high value.

The directing possible relations are listed above. (Note that these are only directing advices).

\section{PART I. PATIENT'S PAIN SENSITIVITY}

- $\quad$ Patient firmly shut off the eyes before specific parts of the procedure (anaesthetic injection, use of forceps etc.).

- Patient declared that anaesthetics hardly affected him in the past.

- $\quad$ Patient asks for more intensive anaesthetics.

- $\quad$ Patient felt pain during the procedure.

- Other recognizable options.

1

2

3

\section{PART II. PATIENT'S STRESS}

- Patient looked nervous before and/or during the procedure.

- Patient was swelling before/during the procedure.

- Patient's respiratory rate increased before/during the procedure.

- Patient reported that he/she is feeling stressful before/during the procedure.

- Other recognizable options.
1
2
3

\section{PART III. PATIENT'S FEAR}

- Patient did not or hardly opened mouth, when asked.

- Patient did not come or scheduled later appointment due to his fear (patient's given information).

- Patient asked to stop the procedure or cancelled it just before the start, due to fear.

- $\quad$ Patient asked many questions about the procedure itself and about the operating surgeon.

- Other recognizable options. 
Appendix 3. The final composition of Universal Scale in Oral Surgery for psycho-emotional status rating.

\section{PATIENT'S PART OF USOS}

Instruction: Please circle one numerical choice next to every following question.

Numerical meanings are listed above:

1 - disagree/low value.

2 - neither agree or disagree/the middle value.

3 - agree/high value.

1. Rate the highest pain in your previous oral surgery procedure (rate the pain level as 1 if you never had such a procedure before).

$$
1
$$

3

2. Rate the highest pain that you are expecting in upcoming oral surgery procedure.

$$
123
$$

3. I am feeling helpless during the procedures in oral surgery.

$$
123
$$

4. My heart beats faster before the surgical procedure.

$$
123
$$

5. My respiratory rate is higher before the surgical procedure.

123

6. Rate the intention of cancelling the appointment of oral surgery procedure.

1

2

3

\section{DOCTOR'S PART OF USOS}

Instruction: Rate the patient's pain sensitivity, stress and fear according to seen response in numerical rating.

Numerical rating meanings are listed above:

1 - low value.

2 - the middle value.

3 - high value.

The directing possible relations are listed above. (Note that these are only directing advices).

\section{PART I. PATIENT'S PAIN SENSITIVITY}

- Patient firmly shut off the eyes before specific parts of the procedure (anaesthetic injection, use of forceps etc.).

- Patient declared that anaesthetics hardly affected him in the past.

- $\quad$ Patient asks for more intensive anaesthetics.

- $\quad$ Patient felt pain during the procedure.

- Other recognizable options.

$$
1
$$

\section{PART II. PATIENT'S STRESS}

- $\quad$ Patient looked nervous before and/or during the procedure.

- Patient was swelling before/during the procedure.

- Patient's respiratory rate increased before/during the procedure.

- Patient reported that he/she is feeling stressful before/during the procedure.

- Other recognizable options.

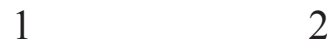$$
1
$$

\section{3}

\section{PART III. PATIENT'S FEAR}

- Patient did not or hardly opened mouth, when asked.

- Patient did not come or scheduled later appointment due to his fear (patient's given information).

- Patient asked to stop the procedure or cancelled it just before the start, due to fear.

- Patient asked many questions about the procedure itself and about the operating surgeon.

- Other recognizable options.

$$
1
$$




\section{To cite this article:}

Astramskaite I, Pinchasov G, Gervickas A, Sakavicius D, Juodzbalys G.

Validation of Universal Scale in Oral Surgery (USOS) for Patient's Psycho-emotional Status Rating

J Oral Maxillofac Res 2017;8(4):e2

URL: http://www.ejomr.org/JOMR/archives/2017/4/e2/v8n4e2.pdf

doi: $10.5037 /$ jomr.2017.8402

Copyright () Astramskaite I, Pinchasov G, Gervickas A, Sakavicius D, Juodzbalys G. Published in the JOURNAL OF ORAL \& MAXILLOFACIAL RESEARCH (http://www.ejomr.org), 31 December 2017.

This is an open-access article, first published in the JOURNAL OF ORAL \& MAXILLOFACIAL RESEARCH, distributed under the terms of the Creative Commons Attribution-Noncommercial-No Derivative Works 3.0 Unported License, which permits unrestricted non-commercial use, distribution, and reproduction in any medium, provided the original work and is properly cited. The copyright, license information and link to the original publication on (http://www.ejomr.org) must be included. 